\title{
A Comparative Study of Anxiety Level of Senior Citizens of Himachal Pradesh and Uttar Pradesh State of India
}

\author{
Dr. Ashwani Kumar* \\ Dept. Phy. Edu., NNPG, College, Nawabganj Gonda (U.P)-INDIA
}

*Corresponding Author: Dr. Ashwani Kumar, Dept. Phy. Edu., NNPG, College, Nawabganj Gonda (U.P)-INDIA

\begin{abstract}
The main objective of the study was to compare the Anxiety Level of Senior Citizens of Himachal Pradesh and Uttar Pradesh State of India. 2000 sample were selected on the bases of simple random method viz: 1000 of each State. 500 male and 500 female gender wise categories were selected of each state. The study was conducted by using the Standardized Questionnaire for measuring the Anxiety level of Senior Citizens i.e.: Taylor Manifest Anxiety Scale (TMAS). The Chi Square $\left(\chi^{2}\right)$ approved significant difference in anxiety of male and female of both states, as the calculated $x 29.257$ and 7.382 is found significant at 0.05 level of significance.
\end{abstract}

Keywords: Anxiety level, Senior Citizens of H.P. \& U.P. State.

\section{INTRODUCTION}

Anxiety is an emotion characterized by an unpleasant state of inner turmoil, often accompanied by nervous behavior, such as pacing back and forth, somatic complaints, and rumination. It is the subjectively unpleasant feelings of dread over anticipated events, such as the feeling of imminent death. Anxiety is not the same as fear, which is a response to a real or perceived immediate threat, whereas anxiety is the expectation of future threat. Anxiety is a feeling of uneasiness and worry, usually generalized and unfocused as an overreaction to a situation that is only subjectively seen as menacing. It is often accompanied by muscular tension, restlessness, fatigue and problems in concentration. Anxiety can be appropriate, but when experienced regularly the individual may suffer from an anxiety disorder.

\section{OBJECTIVE OF THE STUDY}

The main objective of the study was to compare the Anxiety level of Senior Citizens living in Himachal Pradesh and Uttar Pradesh State.

\subsection{Hypothesis of the Study}

It was hypothesized that there will be significant difference in between Anxiety level of Senior Citizens living in Himachal Pradesh and Uttar Pradesh State.

\section{DESIGN OF THE STUDY}

2000 sample were selected on the bases of simple random method viz: 1000 of each State. 500 male and 500 female gender wise categories were selected of each state. The study was conducted by using the Standardized Questionnaire for measuring the Anxiety level of Senior Citizens i.e.: Taylor Manifest Anxiety Scale (TMAS).

\subsection{Statistical Analysis and Interpretations of the Data}

Table1. Gender wise Anxiety Level of Senior Citizens of Himachal Pradesh and Uttar Pradesh State

\begin{tabular}{|c|c|c|c|c|c|}
\hline \multirow{2}{*}{ Sr. No. } & Category & \multicolumn{2}{|c|}{ Male } & \multicolumn{2}{c|}{ Female } \\
\cline { 3 - 6 } & & H. P. & U. P. & H. P. & U. P. \\
\hline 1. & High Score & $97(19.40)$ & $121(24.2)$ & $101(20.20)$ & $113(22.60)$ \\
\hline 2. & Intermediate Score & $314(62.80)$ & $321(64.20)$ & $323(64.60)$ & $339(67.80)$ \\
\hline 3. & Low Score & $89(17.80)$ & $58(11.60)$ & $76(15.20)$ & $48(9.60)$ \\
\hline \multicolumn{2}{|c|}{9.257} & \multicolumn{2}{|c|}{7.382} \\
\hline
\end{tabular}

Figure in parenthesis indicates the percentage, df. $=2$, tab. $=5.991$ at 0.05 level of significance 
The anxiety is one of the vital components of psychology while measuring the psychological condition of the male and female senior citizens. The above table clarifies that male (U.P. $64.20 \%$ \& H.P. 62.80\%) and female (U.P. 67.80\% \& H.P. 64.60\%) of both states in majority has scored at intermediate level, which meant that male and female senior citizens of both states in majority have intermediate anxiety level.

Table also shows that male of Uttar Pradesh (24.2\%) were found more anxious than male senior citizens of H.P. (19.40\%), while the female of U.P. (22.60\% ) were found slightly anxious than females of H.P. (20.20\% ), which shows that anxiety may be differed in male and female.

The Chi Square $\left(\chi^{2}\right)$ also approved significant difference in anxiety of male and female of both states, as the calculated $\mathrm{x}^{2} 9.257$ and 7.382 is found significant at 0.05 level of significance, which meant that male and female of U.P. and H.P. differed significantly in respect to their anxiety level.

The male and female senior citizen both imparts an important role as centralized administrator or liaison officer in family setup. The studies shows that role of female in family setup is considered more effective and important than male.

The experts suggest that in family setup anxiety is often reported from family members and peers. In day to day life, there many factors which make worried the senior members worried and tense. The unemployment of family caregivers, misunderstanding in relationships and lack of adjustment are some major factors responsible for increased anxiety level in older adults. The people of Himachal Pradesh still believe in joint family setup, while the people of Uttar Pradesh disagree with joint family approach. Comparatively, more care takers are available for older adults in joint family than single family. That's why the male and female senior citizens of Uttar Pradesh were found more anxious than Himachali counterparts.

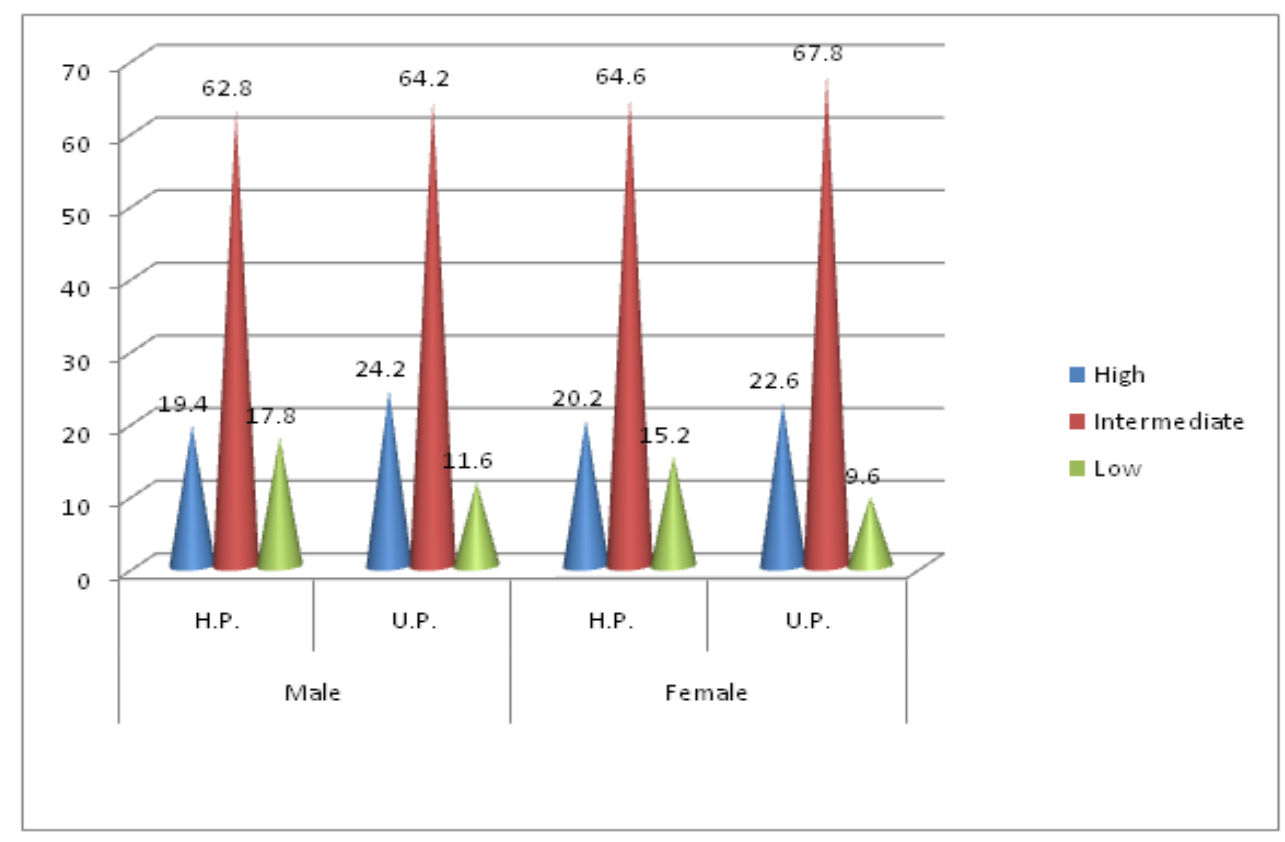

Figure1

\section{FINDINGS OF THE STUDY}

\section{The followings were the main findings of the study}

- The male and female senior citizens of both states in majority have showed intermediate anxiety level [male (U.P. 64.20\% \& H.P. 62.80\%) female (U.P. 67.80\% \& H.P. 64.60\%)].

- male of Uttar Pradesh (24.2\%) were found more anxious than male senior citizens of H.P. $(19.40 \%)$, while the female of U.P. (22.60\%) were found slightly anxious than females of H.P. (20.20\%), which shows that anxiety may be differed in male and female.

- The Chi Square $\left(\chi^{2}\right)$ approved significant difference in anxiety of male and female of both states, as the calculated $x^{2} 9.257$ and 7.382 is found significant at 0.05 level of significance. 


\section{REFERENCES}

[1] Association (2013). Diagnostic and Statistical Manual of Mental Disorders (Fifth ed.). Arlington, VA: American Seligman, M.E.P.; Walker, E.F.; Rosenhan, D.L. Abnormal psychology (4th ed.). New York: W.W. Norton \& Company.

[2] Davison, Gerald C. (2008). Abnormal Psychology. Toronto: Veronica Visentin. ISBN 978-0-470-84072-6.

[3] American Psychiatric Psychiatric Publishing. ISBN 978-0-89042-555-8.

[4] Buchberger B, Huppertz H, Krabbe L, Lux B, Mattivi JT, Siafarikas A (2016). "Symptoms of depression and anxiety in youth with type 1 diabetes: (Systematic Review). doi:10.1016/j.psyneuen.2016.04.019. PMID 27179232.

[5] Grigsby AB, Anderson RJ, Freedland KE, Clouse RE, Lustman PJ (2002). "Prevalence of anxiety in adults with diabetes: a systematic review". J Psychosom Res (Systematic Review). 53 (6). PMID 12479986.

[6] Zingone F, Swift GL, Card TR, Sanders DS, Ludvigsson JF, Bai JC (Apr 2015). "Psychological morbidity of celiac disease: A review of the literature". United European Gastroenterol J (Review). 3 (2).

[7] Molina-Infante J, Santolaria S, Sanders DS, Fernández-Bañares F (May 2015). "Systematic review: noncoeliac gluten sensitivity". Aliment Pharmacol Ther (Systematic Review). 41 (9).

Citation: Dr. Ashwani Kumar. " A Comparative Study of Anxiety Level of Senior Citizens of Himachal Pradesh and Uttar Pradesh State of India" International Journal of Sports and Physical Education (IJSPE), vol 4, no. 1, 2018, pp. 4-6. doi:http://dx.doi.org/10.20431/2454-6380.0401002.

Copyright: (C) 2018 Authors. This is an open-access article distributed under the terms of the Creative Commons Attribution License, which permits unrestricted use, distribution, and reproduction in any medium, provided the original author and source are credited. 